\title{
The first phase insulin response to intravenous glucose is highly reproducible
}

\author{
G. Rayman, P.Clark, A.E.Schneider and C.N.Hales \\ Department of Clinical Biochemistry, Addenbrooke's Hospital, Cambridge, UK
}

\begin{abstract}
Summary. To determine the reproducibility of the first phase insulin response to intravenous glucose, ten normal subjects underwent two intravenous glucose tolerance tests separated by at least two weeks. Intravenous dextrose $(0.3 \mathrm{~g} / \mathrm{kg})$ was administered over $2 \mathrm{~min}$ by continuous infusion and arterialised-venous samples were taken from a retrogradely cannulated hand vein in the opposite arm. Within subjects, median coefficient of variation for the 3 min insulin was $4.0 \%$ (range 1.2-24.3\%) and median coefficient of variation for the $0-10 \mathrm{~min}$ area was $6.7 \%$ (range $1.7-18.8 \%$ ). These coeffi-
\end{abstract}

cients of variation are close to those of the assay itself $(<10 \%)$. Despite this, between subject responses varied by greater than sixfold. In conclusion, contrary to previous reports the intravenous glucose tolerance test is highly reproducible. This makes it a very valuable tool for further studies of the pathogenesis of diabetes.

Key words: Acute phase insulin response, first phase insulin response, intravenous glucose tolerance test, reproducibility
Slow metabolic decompensation over many years prior to diagnosis appears to be a feature of both Type 1 (insulindependent) and 2 (non-insulin-dependent) diabetes mellitus $[1,2]$. The ability to detect reliably early changes in Beta-cell function and reserve may therefore be of major importance to understanding the pathogenesis of the disease and relevent to intervention. In both types of diabetes, impairment of the first phase insulin response to intravenous glucose (IVGTT) is one of the earliest detectable abnormalities [3, 4]; the test has thus gained increasing importance in cross-sectional and longitudinal studies. Yet surprisingly the recent studies by Smith et al. [5] and Bardet et al. [6] are apparently the first to have examined the reproducibility of the first phase response. Both studies report poor reproducibility and concluded that appropriate restraint be exercised in the interpretation of the test. In these studies the assessment of the insulin response and its reproducibility was based on assay of venous blood samples. No steps were taken to minimise the effect of tissue extraction on the venous insulin concentrations. In this study we have examined the reproducibility of the first phase insulin response to intravenous glucose using arterialized venous blood, paying particular attention to the method of blood sampling.

\section{Subjects, materials and methods}

The study group consisted of ten healthy normal subjects, five male and five female aged 24 to 42 years (mean \pm SD; $31.7 \pm 6.4$ years). None had a family history of diabetes or other autoimmune disorders and none were smokers. All subjects had a normal oral glucose tolerance, were on a normal diet and were taking no medications.

The studies were conducted between 08.00 and 09.00 hours after an overnight fast, and the subjects were asked to abstain from alco- hol for the previous $24 \mathrm{~h}$. The study was approved by the District Ethical Committees of the Cambridge and the East Suffolk Health Authorities.

In each subject two IVGTT's were performed, separated by at least 2 weeks but no more than 4 months. For the test, dextrose was administered into a large antecubital vein and blood was sampled from a vein on the dorsum of the opposite hand. To arterialize the venous blood, the hand was placed in a water bath held at a constant temperature of $43^{\circ} \mathrm{C}$, for 10 min prior to the start of the infusion and kept there until the end of the study [7]. To ensure that only blood from the hand was sampled the vein was retrogradely cannulated. Dextrose in a $50 \%$ solution was administered in a dose of $0.3 \mathrm{~g} / \mathrm{kg}$ body weight over $2 \mathrm{~min}$ by constant infusion. Blood was sampled at times $0,1,2,3,4,5,6,8$ and 10 min from the start of the dextrose infusion.

Plasma glucose was determined using the hexokinase method [8] which had an inter-assay coefficient of variation $(\mathrm{CV})$ of $2.7 \%$. For insulin assay, samples were collected into heparinised tubes, centrifuged at room temperature and stored at $-20^{\circ} \mathrm{C}$ for later analysis. All samples from the same individual were analysed in the same assay. Insulin was assayed using a sensitive and highly specific monoclonal antibody based immunoradiometric assay and standardised against the first International Reference Preparation 66/304 [9]. The interassay $\mathrm{CV}$ of the assay was $<10 \%$ over the concentration range $20-476 \mathrm{pmol} / \mathrm{l}$.

\section{Statistical analysis}

Differences between the two tests were assessed using the Wilcoxon signed rank test. Between subject variation was determined by measurement of the $C V$. Within subject variation was determined by two methods. For comparison with the results reported by Smith et al. [5] within subject variation was expressed as the median coefficient of variation. A more accurate estimate of within subject $\mathrm{CV}$ is based on the method used for paired samples [10]. In this, the SD for each pair is the difference between tests divided by the square root of 2. The combination of the estimates of the SD for all the subjects studied is a good estimate of the underlying imprecision. Thus: 

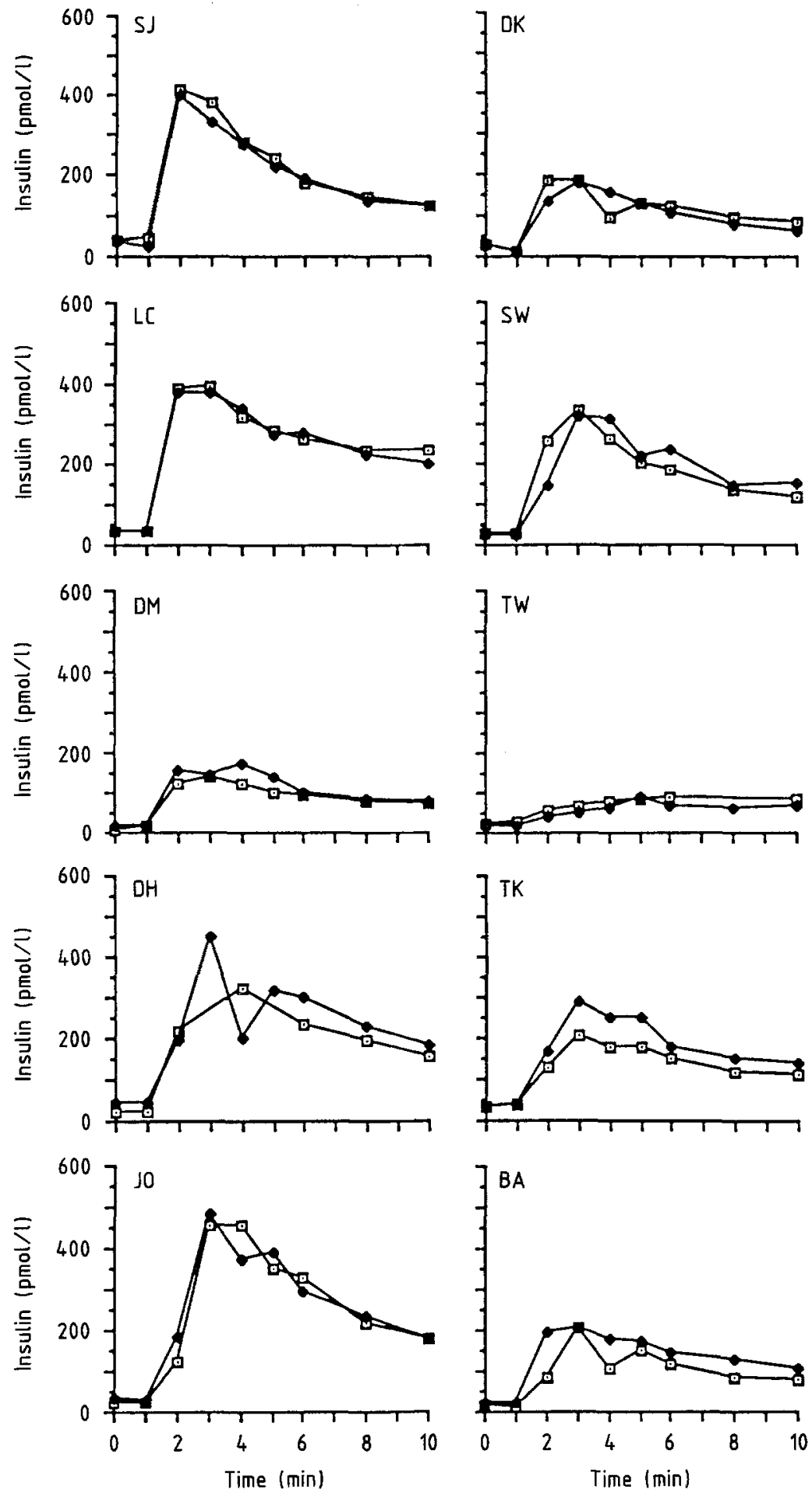

Fig. 1. Graphical descriptions of the first phase insulin responses in all 10 subjects. The first study and second studies are shown as open and filled squares, respectively

mean $\mathrm{SD}=\frac{\sqrt{\sum^{n} \mathrm{SD}_{1}^{2}+\mathrm{SD}_{2}^{2}+\ldots \mathrm{SD}_{n}^{2}}}{n-1}$

Where $n$ is the number of pairs. The mean within subject $C V$ is the mean SD divided by the mean of all the results.

\section{Results}

The 3 min insulin level ( $3^{\prime}$ insulin; pmol/l) and the area under the $0-10 \mathrm{~min}$ curve $\left(0-10^{\prime}\right.$ area; $\left.\mathrm{pmol} \cdot \mathrm{I}^{-1} \cdot 10 \mathrm{~min}^{-1}\right)$ were used as measures of the insulin response. The peak glucose concentration and the area under the $0-10 \mathrm{~min}$ curve $\left(0-10^{\prime}\right.$ area; $\left.\mathrm{mmol} \cdot \mathrm{I}^{-1} \cdot 10 \mathrm{~min}^{-1}\right)$ were used as measures of the changes in glucose.

\section{Glucose changes}

For the whole group there was no difference in the mean peak glucose or mean $0-10^{\prime}$ glucose area for the first and second tests ( $p>0.3$ for each), Table 1 .

Between subject $\mathrm{CVs}$ for the peak glucose were $16.9 \%$ and $17.1 \%$ for the first and second studies, respectively; and $8.4 \%$ and $12.2 \%$ for the $0-10^{\prime}$ glucose areas. 
Table 1. Individual insulin and glucose responses in studies 1 and 2

\begin{tabular}{|c|c|c|c|c|c|c|c|c|}
\hline \multirow[t]{2}{*}{ Subject } & \multicolumn{2}{|c|}{$\begin{array}{l}\text { Peak glucose } \\
\mathrm{mmol} / 1\end{array}$} & \multicolumn{2}{|c|}{$\begin{array}{l}0-10^{\prime} \text { glucose } \\
\mathrm{mmol} \cdot 1^{-1} \\
10 \mathrm{~min}^{-1}\end{array}$} & \multicolumn{2}{|c|}{$\begin{array}{l}3^{\prime} \text { insulin } \\
\mathrm{pmol} / \mathrm{l}\end{array}$} & \multicolumn{2}{|c|}{$\begin{array}{l}0-10^{\prime} \text { insulin } \\
\mathrm{pmol} / 10 \mathrm{~min}\end{array}$} \\
\hline & 1 & 2 & 1 & 2 & 1 & 2 & 1 & 2 \\
\hline SJ & 23.7 & 26.0 & 156 & 171 & 380 & 325 & 1996 & 1920 \\
\hline DK & 22.8 & 24.6 & 164 & 165 & 183 & 180 & 1082 & 989 \\
\hline LC & 22.9 & 22.0 & 166 & 161 & 395 & 375 & 2533 & 2472 \\
\hline SW & 23.4 & 26.8 & 148 & 155 & 332 & 314 & 1753 & 1818 \\
\hline DM & 21.1 & 20.2 & 153 & 120 & 138 & 145 & 856 & 1018 \\
\hline TW & 20.0 & 23.0 & 153 & 175 & 69 & 50 & 710 & 548 \\
\hline DH & 18.3 & 17.7 & 140 & 137 & - & 452 & 2015 & 2223 \\
\hline TK & 30.1 & 27.7 & 183 & 166 & 205 & 290 & 1317 & 1721 \\
\hline $\mathrm{JO}$ & 19.9 & 18.7 & 143 & 133 & 453 & 481 & 2524 & 2558 \\
\hline BA & 16.5 & 17.3 & 144 & 140 & 207 & 208 & 1077 & 1362 \\
\hline Mean & 21.9 & 22.4 & 155 & 152 & 262 & 263 & 1586 & 1663 \\
\hline SD & 3.7 & 3.8 & 13. & 18.6 & 131 & 131 & 670 & 672 \\
\hline
\end{tabular}

Between

subject

\begin{tabular}{lllllllll} 
CV\% & 16.9 & 17.1 & 8.4 & 12.2 & 50.0 & 49.8 & 42.2 & 40.4 \\
\hline
\end{tabular}

$\mathrm{CV}=$ coefficient of variation

Within subject variation of the peak glucose expressed as median CV was $4.9 \%$ (range $2.4-9.9 \%$ ). Within subject variation calculated using the second method described gives a mean $\mathrm{CV}$ of $6.5 \%$. Within subject variation of the $0-10^{\prime}$ glucose area expressed as median $\mathrm{CV}$ was $4.7 \%$ (range $1.5-15.7 \%$ ) and mean CV of $8.5 \%$.

\section{First phase insulin response}

The graphs in Figure 1 show the individual insulin responses. Three min insulin values and $0-10^{\prime}$ insulin areas are shown in Table 1. For the whole group 3' insulin (262 and $263 \mathrm{pmol} / \mathrm{l})$ and $0-10^{\prime}$ areas (1586 and $1663 \mathrm{pmol} \cdot \mathrm{1}^{-1} \cdot 10 \mathrm{~min}^{-1}$ ) were not significantly different when study 1 and 2 were compared; $p>0.3$ for both.

The between subject $\mathrm{CV}$ for the $3^{\prime}$ value was $42 \%$ and $40 \%$ for studies 1 and 2 , respectively. Between subject CV for the $0-10^{\prime}$ insulin area was $50 \%$ for each of the studies.

Within subject variation expressed as median $\mathrm{CV}$ (range) was $4.0 \%\left(1.2-24.3 \%\right.$ ) for the $3^{\prime}$ value and $6.7 \%$ $(1.7-18.8 \%)$ for the $0-10^{\prime}$ insulin area. When expressed as mean $\mathrm{CV}$ using the method based on duplicates the figures were $10.5 \%$ for the $3^{\prime}$ value and $8.8 \%$ for the $0-10^{\prime}$ insulin.

\section{Discussion}

This study shows that the within subject first phase insulin response to intravenous glucose is highly reproducible in normal subjects. These findings contrast with those of Smith et al. [5] and Bardet et al. [6] who found poor reproducibility. In the study of Smith et al., of the four different methods used to estimate insulin response, the $0-10^{\prime}$ insulin area gave the smallest median CV. Nevertheless, this was still unacceptably large; $22 \%$ (range $3-55 \%$ ). Bardet et al. found the sum of the 4 and 5 min insulin levels (timed from the end of the infusion) gave the lowest within subject CV. This was also unacceptably high at $29 \%$. In comparison in the present study the median within subject
CVs for the 3 insulin and insulin areas were $4.0 \%$ (range $1.2-24.3 \%$ ) and $6.7 \%$ (range $0.9-18.8 \%$ ), respectively.

Because of the very rapid rise and fall in insulin concentrations (Fig. 1) slight errors in timing or reduced venous blood flow (due to stress-induced vasoconstriction, partial venous obstruction by antegrade cannulation or venous compression by the fixing tape) may have substantial effects on the reproducibility. We believe that the improved within subject variability of the present study can be explained by the use of arterialized venous blood, retrograde venous cannulation of hand veins and meticulous timing of the sampling intervals. Heating the hand skin to $43^{\circ} \mathrm{C}$ results in a substantial increase in blood flow due to a direct effect on the blood vessels and the opening of arterio-venous anastomoses. The decreased transit time minimises the effect that tissue insulin extraction would otherwise have on the insulin concentration of the venous blood. Toensure that only arterialized blood was sampled, hand veins were used and the cannula was inserted retrogradely to avoid drawing blood from proximal veins draining deeper unheated tissues such as forearm muscle.

In all except one subject (TW - Fig. 1) peak insulin responses occurred at or between the second and fourth min. This subject was very stressed during both IVGTTs as suggested by pale cold sweaty skin. Despite the measures to induce high skin blood flow, blood could only be drawn very slowly from the vein suggesting reduced hand blood flow. The increased microvascular tissue transit time could explain the apparently poor insulin response.

In this study we have used a highly sensitive and specific assay for insulin. We do not think that the improved results are related to the assay, as the precision for our assay is similar to the precision quoted by both Smith et al. [5] and Bardet et al. [6] in their studies. In addition samples from the present study were kindly analysed by the laboratory involved in the study by Smith et al. Using their assay they confirmed the good within subject reproducibility (personal communication).

Smith et al. [5] used a fixed dose of $25 \mathrm{~g}$ of dextrose. This would not affect the within subject variation as the same dose is used in the two tests, however it may explain why a large between subject variation in the glucose areas was found ( $27 \%$ for each of the two IVGTT's). We have used a weight-dependent dose assuming that the blood volume and hence glucose concentration would be related to body weight. This gave a better between subject variation in the glucose areas $(8.4 \%$ and $12.2 \%$ for the two IVGTTs). Bardet et al. also used a weight dependent dose but did not report on the reproducibility of the glucose changes.

Despite achieving similar plasma glucose challenges in the different subjects, between subject insulin responses were still extremely variable, insulin areas and $3^{\prime}$ insulin values differing as much as five-to six fold. What determines this large variation in response is a matter of further research.

In conclusion, using the methods we have described, the first phase insulin response is highly reproducible. The use of this test in prospective studies in high risk groups may allow early identification of those who would benefit from early intervention. 


\section{References}

1. Tarn AC, Smith CP, Spencer KM, Bottazzo GF, Gale EAM (1987) Type I (insulin-dependent) diabetes: a disease of slow clinical onset? Br Med J 1:342-345

2. Fajans SS (1973) Identification of chemical diabetes: the definition of chemical diabetes. Metabolism 22: 211-217

3. Srikanta S, Ganda OP, Gleason RE, Jackson RA, Soeldner JS, Eisenbarth GS (1984) Pre-Type I diabetes. Linear loss of beta cell response to intravenous glucose. Diabetes 33: 717-720

4. Lerner RL, Porte D (1972) Acute and steady state insulin responses to glucose in nonobese diabetic subjects. J Clin Invest 51: $1624-1631$

5. Smith CP, Tarn AC, Thomas JM, Overkamp D, Corakci A, Savage MO, Gale EAM (1988) Between and within subject variation of the first phase insulin response to intravenous glucose. Diabetologia 31: 123-125

6. Bardet S, Pasqual C, Maugendre D, Remy J-P, Charbonnel B, Sai $P$ (1989) Inter and intra individual variability of acute insulin response during intravenous glucose tolerance tests. Diabete Metab 15: 233-241
7. Forster HV, Dempsey JA, Thompson J, Vidruk E, doPico GA (1972) Estimation of arterial $\mathrm{PO}_{2}, \mathrm{PCO}_{2}, \mathrm{pH}$ and lactate from arterialized venous blood. J Appl Phys 32: 134-137

8. Kunst A, Draeger B, Ziegenhern J (1983) U-V methods with hexokinase and glucose 6-phosphate dehydrogenase. In: Bergmeyer HU (ed) Methods of enzymatic analysis, vol VI. Verlag Chemie, Deerfield FL, pp 163-172

9. Sobey WJ, Beer SF, Carrington CA, Clark PM, Frank BH, Gray IP, Luzio SD, Owens DR, Schneider AE, Siddel K, Temple RC, Hales CN (1989) Sensitive and specific two-site immunoradiometric assay for the human insulin, and proinsulin, 6566 split and 32-33 split proinsulins. Biochem J 260: 535-541

10. Raggat PR (1989) Duplicates or singletons? An analysis of the need for replication in immunoassay and a computer program to calculate the distribution of outliers, error rate and the precision profile from assay duplicates. Ann Clin Biochem 26:23-37

Received: 15 May 1990

Dr. G. Rayman

Addenbrooke's Hospital

Cambridge CB 25 DA, UK

\section{Announcements}

Diabetes and Native Peoples: International Issues in Education, Treatment, and Prevention

This conference will be held on November 7-9, 1990 at the Holiday Inn-Downtown in Minneapolis, MN, USA. Continuing education credit will be offered for physicians, nurses, and pharmacists. A $\$ 50$ registration fee is required and covers the cost of the banquet dinner, Pow Wow, and continuing education units. For further information please contact: Dr. Robert Young, NARTC, 1642 E. Helen St., Tucson, AZ 85719, Tel.: (602) 621-5560 (USA). Virginia Toulouse, Assembly of First Nations-Diabetes Conference, 47 Clarence St., 3 rd Floor, Atrium Building, Ottawa, Ontario K1N 9K1, Tel.: (613) 236-0673 (Canada).

India - USA Symposium and Workshop on Endocrinology, Metabolism and Diabetes

The above mentioned symposium will take place from December 27-31, 1990 at the All India Institute of Medical Sciences. For further information please contact: Dr. N. Kochupillai, Organising Secretary, EMD-90, c/o Dept. of Endocrinology Metabolism and Diabetes, All India Institute of Medical Sciences, New Delhi 110029, India. Tel.: 651612 or 661123 extn. 237; Telex: 31-730 42 AIMS IN; Fax: 91-116863153.

\section{Fifth Milano International Meeting on Diabetes}

This meeting will be held on March 21-23, 1991 in Milano, Italy. The main topics will be: Glucose transporter and insulin action; Diabetic nephropathy; Genetic epidemiology; Lipoprotein; Immunology of diabetes. Deadline for abstract presentation: December 1, 1990. For further information please contact: Piero Micossi, M.D. - Direzione Scientifica, Istituto Scientifico H San Raffaele, Via Olgettina, $60 \mathrm{I}$ 20132 Milano, Italy. Tel.: 02/21 702759, 02/21 702454, 02/217027 53; Fax: 02/21 702752 or 21702482 .

\section{Macrovascular Complications of Diabetes Mellitus. Satellite Sym-} posium of the 14th IDF Congress

To take place on June 20-22, 1991 in Charleston, South Carolina. Registration deadline: February 28, 1991. For further information please contact: Dr. M. Lopes-Virella, Veterans Administration
Medica Center, Research Services, 109 Bee Street, Charleston, South Carolina 29403, USA. Tel.: (8 03) 577-5011 extn. 7542

Third International Winter Course I.S. G.D. (International Study Group on Diabetes of Children and Adolescents) "Update on Diabetes in Childhood"

This course will be held on March16-23, 1991 in Passo del Tonale, (Trento) Italy. The course is addressed to physicians who wish to aquire a deeper knowledge of diabetes in the young. The course is organised by I.S.G.D. in collaboration with the University of Verona (Italy) and the Beilinson Medical Center at the University of Tel Aviv (Israel). For further information, please contact: L. Pinelli, Servizio di Diabetologia Pediatrica, Policlinico I-37134 Verona, Italy. Tel.: 0039.45.933667; Telefax 0039.45 .8200993$.

\section{Epidemiology and a Etiology of IDDM in the Young}

This symposium will be held on May 12-15, 1991 in a lovely château located in the Paris area (château de Montvillargenne, Chantilly), France. A special social programme will be prepared for all participants. The symposium has received scientific support from INSERM, ISGD and EASD. Deadline for submission of abstracts: December 30, 1990. For further information please contact: Scientific Secretary, Dr. Claire Levy-Marchal, Service de Diabètologie, Hôpital Robert Debré,48, Boulevard Sérurier, F-75019, France. Tel.: 33(1) 40032360; Fax: 33(1) 40032020 .

\section{Nutrition and Diabetes Mellitus: Focus for the 90's}

This symposium will be beld on June 22-23, 1991 in the Hyatt Regency on the Inner Harbor Baltimore, Maryland, USA. This symposium will include presentations by invited speakers on nutrition issues of particular interest in the 1990's such as macronutrient composition and caloric dilution, as well as global issues such as emergence of diabetes and changes in diet in developing countries. The topics, poster sessions, and discussions will provide stimulation for future nutrition/diabetes research. For further information please contact: Liz DeShetler, MS, RD, Diabetes Care Center, Riverside Methodist Hospitals, 3535 Olentangy River Rd., Columbus, OH 43214, USA. Tel.: (614) 488-9334 